( Т. Ю. Киричок, д.т.н., професор, Т. Є. Клименко, К.Т.н., ст. викладач, КПІ ім. Ігоря Сікорського, Київ, Україна

\title{
ПРОГРАМНЕ ЗАБЕЗПЕЧЕННЯ ДЛЯ ФІЛЬТРАЦІї НЕРІВНОСТЕЙ ПРОФІЛЮ ПОВЕРХНІ ПАПЕРУ
}

\author{
Розроблено програмне забезпечення для фільтрації \\ нерівностей профілю поверхні незадрукованого та задру- \\ кованого паперу, що дозволяє отримати відфільтровані \\ профілограми, виключивши з профілю такі фактори, \\ як перешкоди та викликані похибками випадкових \\ вібрацій обладнання.
}

Ключові слова: папір; шорсткість паперу; профілограма поверхні паперу; фільтрація нерівностей профілю поверхні; структура поверхні паперу; похибки та перешкоди приладу; фільтр Гауса; якість відбитків.

\section{Постановка проблеми}

Надзвичайно важливим для отримання адекватного опису періодичних процесів та структур, в тому числі для оцінки профілю поверхні паперу є коректна цифрова обробка сигналу задля визначення істинних його параметрів, оскільки сигнали зазвичай спотворюються через вплив перешкод або середовища, через яке сигнал передається. Тому фільтрація профілю є одним з важливих етапів оцінки профілю поверхні паперу [1]. Під фільтрацією розуміють методи (електричні, оптичні, механічні, математичні) для вибору необхідної інформації із загального профілю поверхні. Для визначення впливу мікрогеометрії на експлуатаційні властивості необхідно спочатку виключити з профілю такі фактори, як перешкоди та похибки приладу. Вплив перешкод, особливо з боку навколишнього середовища, неминучий при записі профілів, до того ж для повного нівелювання похибки приладу досліджуваного зразка необхідна велика кількість часу. Отже, необхідно розробити математичну модель для фільтрації нерівностей профілю поверхні паперу.

\section{Мета роботи}

Розробити методику цифрової обробки профілограм поверхні паперу для подальшого встановлення взаємозв'язку параметрів паперу з якістю відбитків.

\section{Аналіз попередніх досліджень}

Основними джерелами шумів і перешкод під час профілографування, в тому числі поверхні паперу $є[2,3]:$ вплив змін параметрів контакту голки з поверхнею паперу, що призводить до дрейфу постійних складників; хвилястість аркуша; вплив мережевих

(C) $2017 \mathrm{p}$. 
перешкод із частотою гармонік мережевої напруги; вплив коливань стола вимірювань.

Методи фільтрації ґрунтуються на використанні різниці властивостей корисного сигналу і шумової компоненти (перешкоди).

Для фільтрації використовують низку алгоритмів і методів, які мають бути адаптованими до способу отримання сигналу та його властивостей [4].

Поширеними підходами до обробки сигналів $є$ :

- синхронне усереднення чи усереднення за ансамблем для багатьох реалізацій [5];

- медіанна фільтрація [6];

- сплайн-фільтрація [7];

- фільтрація за Вінером та Чебишевим [4];

- адаптивна фільтрація [8];

- вейвлет-перетворення [9];

- Фурьє-перетворення [9].

Ці всі види фільтрів знаходять своє застосування у різноманітних галузях. Для оброблення профілограм оброблених поверхонь деталей машин та механізмів авторами [10] запропоновано після оцифровування графіка профілограми використовувати фільтр Гаусса для оцінки геометричних параметрів якості поверхні і дослідження її параметрів і характеристик. Такий фільтр застосовують у випадках, коли перешкоди піддаються нормальному розподілу [11]. Такий підхід, видається, доцільно застосувати для оцифровування профілограм паперу.

\section{Результати проведених досліджень}

Для проведення експериментальних досліджень використані профілограми поверхонь різних видів паперу, які були отримані в попередніх дослідженнях [12, 13] за допомогою профілометра з індуктивним перетворювачем, модель 296, для вимірювання профілю та параметрів шорсткості поверхні.

За основу розглянемо функцію $f(x)$ таку, що виконує умови:

1. $f(0)$ дає максимум функції $f$ на всій осі;

2. $\lim _{n \rightarrow-\infty} f(x)=\lim _{n \rightarrow \infty} f(x)=0$;

3. $\int_{-\infty}^{\infty} f(x) d x=1$;

4. $f(x) \geq 0$ для всіх $x$ (необов'язкова умова).

За приклад взято фільтр Гауса

[14]: $f(x)=\frac{1}{\sqrt{2 \pi}} e^{\frac{-x^{2}}{2}}$.

Щоб відфільтрувати профіль $h(x)$, виконано перетворення

$$
r(x)=\int_{-\infty}^{\infty} h(x+t) f(t) d t .(1)
$$

Нехай функція $\mathrm{h}(\mathrm{x})$ має такий вигляд, як показано на рис. 1.

Початкова функція $\mathrm{h}(\mathrm{x})=\mathrm{r}(\mathrm{x})+$ $+s(x)$, тобто $h(x)$ складається з доданків $r(x)$ та $s(x)$, де $r(x)-$ «рельєфна» складова (relief), a s(x) «шорстка» (sharp) складова. Функцію профілю $r(x)$ та нерівностей $\mathrm{s}(\mathrm{x})$ після фільтрації показано на рис. 2.

При перетворенні $\mathrm{h}(\mathrm{x}) \rightarrow \mathrm{r}(\mathrm{x})$ отримаємо, що

$$
\begin{aligned}
& r(x)=\int_{-\infty}^{\infty} h(x+t) f(t) d t= \\
& =\int_{-\infty}^{\infty} r(x+t) f(t) d t+ \\
& +\int_{-\infty}^{\infty} s(x+t) f(t) d t
\end{aligned}
$$




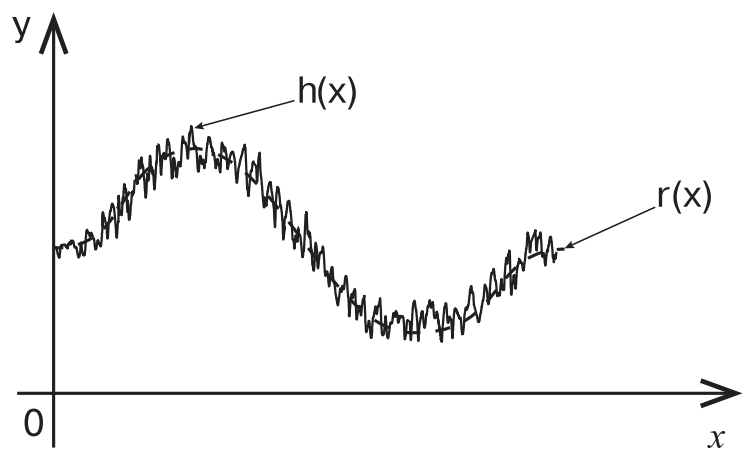

Рис. 1. Початкова функція профілю $\mathrm{h}(\mathrm{x})$

Перший додаток мало відрізняється від $r(x)$, тому що $r(x)$ змінюється плавно, а значить в точках $(x+t)$, близьких до x (для малих $t)$, вона має майже те саме значення, що і в х. В далеких точках $r(x+t)$ мало впливає на значення $\int_{-\infty}^{\infty} r(x+t) f(t) d t$, такякзаумовою (2) $f(t)$ прагне до нуля, при $\mathrm{t} \rightarrow-\infty$ та при $\mathrm{t} \rightarrow \infty$. Другий додаток близький до нуля, тому що $\mathrm{s}(\mathrm{x})$ мало ухиляється від нуля та вібрує (та його від'ємні значення компенсують додатні). Тому $\int_{-\infty}^{\infty} h(x+t) f(t) d t \approx r(x)$.
Розроблено програмне забезпечення на основі програмного пакету Free Pascal [15]. Вхідні дані для введення у програму це координати профілю поверхні паперу. На рис. 3 представлено графіки профілю поверхні паперу, профіль а - побудований по вхідним даним, профіль б побудований на основі аналітичного розрахунку після фільтрації, профіль в - побудований з залишкових нерівностей. Для того, щоб зробити розрахунок даних в програмі реалізований алгоритм, блок-схема якого представлена на рис. 4.

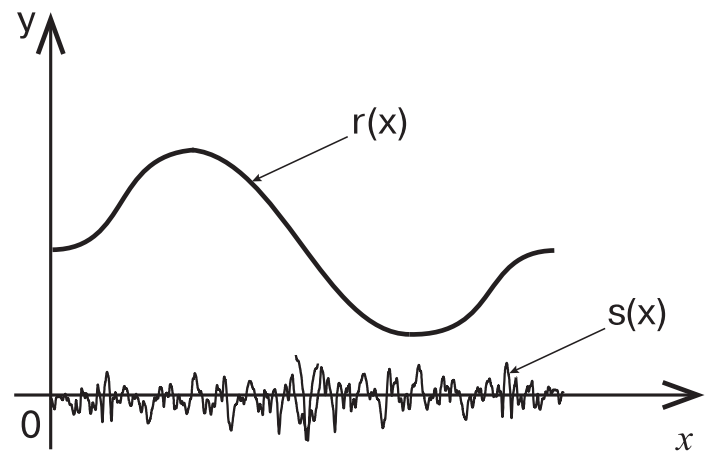

Рис. 2. Функція профілю $r(x)$ та нерівностей $s(x)$ після фільтрації 


\section{Висновки}

Розроблено програмне забезпечення для фільтрації нерівностей профілю поверхні незадрукованого або задрукованого паперу з використанням фільтру Гаусса, що дозволяє отримати профіло- грами, виключивши з профілю такі фактори, як перешкоди та похибки, викликані випадковими вібраціями, розраховувати відповідні показники шорсткості, та встановити в подальшому взаємозв'язок з якістю відбитків на цьому папері.

\section{Список використаної літератури}

1. Shapiro L. G. Computer Vision / L. G. Shapiro, G. C. Stockman. Prentence Hall, 2001. C. 137-150.

2. Бабаджанов Л. С. Меры толщины тонких покрытий и их измерение способом совмещения профилограмм / Л. С. Бабаджанов // Измерительная техника. 2003. № 4. С. 10-12.

3. Лищенко Н. В. Частотный анализ неровностей поверхности и вибраций при её обработке / Н. В. Лищенко, В. В. Нежебовский, В. П. Ларшин // Перспективні технології та прилади. 2015. Вип. 7. С. 72-80. Режим доступу: http://nbuv.gov.ua/UJRN/ptp_2015_7_17.

4. Устименко В. О. Підвищення якості фільтрації електрокардіосигналу за допомогою фільтрів Вінера та Чебишева / В. О. Устименко; К. А. Клочко, А. В. Бідун // Наукові праці ВНТУ. 2017. № 2. 8 с.

5. Патюков В. Г. Помехоустойчивые измерители частотно-временных параметров сигналов // Измерительная техника. 2003. № 4. С. 45-47.

6. Нгуен Т. Ф. Параллельная реализация алгоритмов фильтрации космических изображений / Т. Ф. Нгуен, А. Ю. Шелестов // Проблемы управления и информатики. 2005. № 2. С. 121-132.

7. Шелевицький І. В. Методи та засоби спайн-технології обробки сигналів складної форми / І. В. Шелевицький. Кривий Ріг: Європейський ун-т, 2002. 304 c.

8. Смеляков К. С. Адаптивна просторова фільтрація зображень / К. С. Смеляков, І. В. Рубан // Системи озброєння і військова техніка. 2008. № 3(15). C. $164-166$.
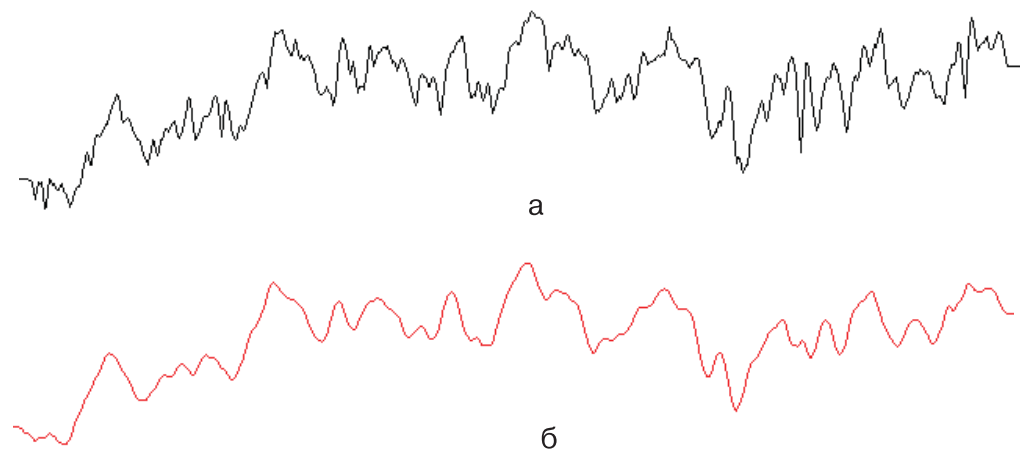

б

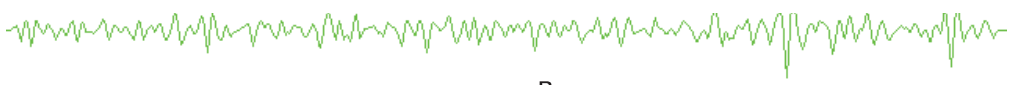
B

Рис. 3. Графіки профілю поверхні паперу: а - початковий профіль, б - профіль аналітично розрахований після фільтрації, в - профіль «залишкових» нерівностей 


\section{ТЕХНОЛОГІЧН І П РО ЦЕ С И}

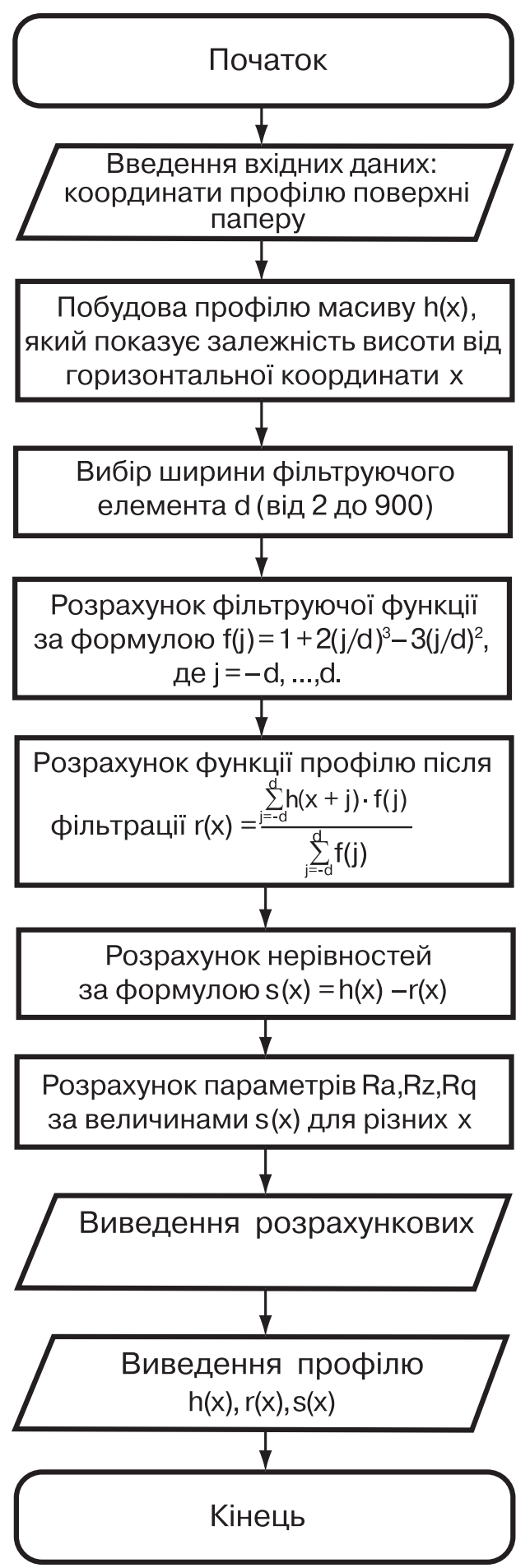

Рис. 4. Алгоритм для фільтрації нерівностей профілю поверхні паперу 
9. Иванов В. Г. Фурье - и вейвлет - анализ изображений в плоскости JPEG-технологий / В. Г. Иванов, М. Г. Любарский, Ю. В. Ломоносов // Проблемы управления и информатики. 2004. № 5. С. 111-124.

10. Каморкин П. А. Применение фильтра Гаусса для определения геометричских параметров качества поверхности профильным методом / П. А. Каморкин // Прогресивні технології і системи машинобудування. 2013. № 1(45)-2(46). С. 139-146.

11. Попов Г. А. Об одном методе низкочастотной фильтрации гидролокационных изображений / Г. А. Попов, Д. А. Хрящёв // Вестник АГТУ. Сер. Морская техника и технология. 2010. № 1. С. 63-68.

12. Киричок Т. Ю. Моделювання структури поверхні банкнотного паперу на основі теорії фракталів / Т. Ю. Киричок, Т. Є. Клименко, О. В. Рибак // Наукові вісті НТуУ «КПІ». К., 2016. № 2. С. 33-42.

13. Киричок Т. Ю. Мікрогеометрія поверхні паперу з водяними знаками / Т. Ю. Киричок, Т. Є. Клименко, Н. Л. Малкуш // Зб. наук. праць «Технологія і техніка друкарства». К., 2009. № 4. С. 130-137. Режим доступу: http://ttdruk.vpi.kpi.ua/article/view/57869.

14. Nixon Mark S. Feature Extraction and Image Processing // Academic Press. 2008. P. 88.

15. Mattias Gaertner. Lazarus for Cross-Platform Development (англ.) // Linux Journal. Belltown Media, Inc., 2009. Iss. 185.

\section{References}

1. Shapiro, L. G. \& Stockman, G. C. (2001). Computer Vision. Prentence Hall, 137-150 [in English].

2. Babadzhanov, L. S. (2003). Mery tolshchiny tonkikh pokrytiy i ikh izmerenie sposobom sovmeshcheniya profilogramm. Journal of Izmeritel'naya tekhnika, 4, 10-12 [in Russian].

3. Lishchenko, N. V. \& Nezhebovskiy, V. V. \& Larshin, V. P. (2015). Chastotnyy analiz nerovnostey poverkhnosti i vibratsiy pri ee obrabotke. Journal of Perspektyvni tekhnolohii ta prylady, 7, 72-80. Retrieved from: http://nbuv.gov.ua/ UJRN/ptp 2015717 [in Russian].

4. Ustymenko, V. O. \& Klochko, K. A. \& Bidun, A. V. (2017). Pidvyshchennia yakosti filtratsii elektrokardiosyhnalu za dopomohoiu filtriv Vinera ta Chebysheva. Journal of Naukovi pratsi VNTU, 2, 8 [in Ukrainian].

5. Patyukov, V. G. (2003). Pomekhoustoychivye izmeriteli chastotno-vremennykh parametrov signalov. Journal of Izmeritel'naya tekhnika, 4, 45-47 [in Russian].

6. Nguen, T. F. \& Shelestov, A. Yu. (2005). Parallel'naya realizatsiya algoritmov fil'tratsii kosmicheskikh izobrazheniy. Journal of Problemy upravleniya $i$ informatiki, 2, 121-132 [in Russian].

7. Shelevytskyi, I. V. (2002). Metody ta zasoby spain-tekhnolohii obrobky syhnaliv skladnoi formy. Kryvyi Rih, Yevropeiskyi un-t, 304 [in Ukrainian].

8. Smeliakov, K. S. \& Ruban, I. V. (2008). Adaptyvna prostorova filtratsiia zobrazhen. Journal of Systemy ozbroiennia i viiskova tekhnika, 3(15), 164-166 [in Ukrainian].

9. Ivanov, V. G. \& Lyubarskiy, M. G. \& Lomonosov, Yu. V. (2004). Fur'e - i veyvlet - analiz izobrazheniy v ploskosti JPEG-tekhnologiy. Journal of Problemy upravleniya i informatiki, 5, 111-124 [in Russian].

10. Kamorkin, P. A. (2013). Primenenie fil'tra Gaussa dlya opredeleniya geometrichskikh parametrov kachestva poverkhnosti profil'nym metodom. Journal of Progresivni tekhnologiï i sistemi mashinobuduvannya, 1(45)-2(46), 139-146 [in Russian]. 
11. Popov, G. A. \& Khryashchev, D. A. (2010). Ob odnom metode nizkochastotnoy fil'tratsii gidrolokatsionnykh izobrazheniy. Journal of Vestnik AGTU. Ser. Morskaya tekhnika i tekhnologiya, 1, 63-68 [in Russian].

12. Kyrychok, T. lu. \& Klymenko, T. le. \& Rybak, O. V. (2016). Modeliuvannia struktury poverkhni banknotnoho paperu na osnovi teorii fraktaliv. Journal of Naukovi visti NTUU 'KPI', 2, 33-42 [in Ukrainian].

13. Kyrychok, T. Iu. \& Klymenko, T. Ie. \& Malkush, N. L. (2009). Mikroheometriia poverkhni paperu z vodianymy znakamy. Journal of $Z b$. nauk. prats 'Tekhnolohiia i tekhnika drukarstva', 4, 130-137. Retrieved from http://ttdruk.vpi.kpi.ua/article/view/57869 [in Ukrainian].

14. Nixon, Mark S. (2008). Feature Extraction and Image Processing. Journal of Academic Press, 88 [in English].

15. Mattias, Gaertner. (2009). Lazarus for Cross-Platform Development. Journal of Linux Journal. Belltown Media, Inc., 185 [in English].

\begin{abstract}
Разработано программное обеспечение для фильтрации неровностей профиля поверхности незапечатанной и запечатанной бумаги, с помощью которого можно получить отфильтрованные профилограммы, исключив из профиля такие факторы, как препятствия и погрешности, вызванные случайными вибрациями используемого оборудования.
\end{abstract}

Ключевые слова: бумага; шероховатость бумаги; профилограмма поверхности бумаги; фильтрация неровностей профиля поверхности; структура поверхности бумаги; погрешности и помехи устройства; фильтр Гаусса; качество оттисков.

The software for filtering roughness of the profile of the surface of unprinted and printed paper was developed which allows receiving filtered profilograms to exclude in the profile the negative impact of the factors such as interference and errors caused by random vibration of equipment.

Keywords: paper; roughness parameters of the paper; paper surface profiligram; filtration of surface profile roughness; structure of the paper surface; inaccuracies and interference of the device; Gaussian filter; quality of the prints. 